\title{
Structure and causes of vegetation change in state and transition model applications
}

\author{
RICARDO M. RODRIGUEZ IGLESIAS AND MORT M. KOTHMANN
}

Authors are post-doctoral research associate and professor, Department of Rangeland Ecology \& Management, Texas A\&M University, College Station, Tex. 77843-2126.

Abstract

State and transition (ST) descriptions of rangeland vegetation dynamics provide information on current perceptions of explicit causes of change in dominant vegetation. Structural attributes of ST applications allow an evaluation of the complexity of the ST model and comparisons with the organization of the traditional succession-retrogression model of secondary succession. An analysis of 29 applications of the ST model revealed consistent trends. The number of transitions connecting states showed a less-than-expected increase with the size of the application. This is probably associated with limitations to interpret complex relationships and a need to produce relatively simple applications. Larger applications exhibited a shift towards stable states with pivotal positions within structures less connected (i.e., with fewer transitions) than expected by chunce for a given number of states. Thus, some stable states assume key intermediary roles as the number of states considered increases. It is debatable whether this is a property of larger systems or an effect of modeling bias. The analysis of causes of vegetation change confirmed current perceptions about the importance of man-related sources of disturbance. Grazing, fire, and control of woody plant species are visualized as the most relevant man-related agents of change. Some ST applications retain autogenic behaviors embedded in transitions in spite of the event-driven nature of the approach. However, the ST model removes autogenic processes from their central role as general causes for vegetation change. This approach is theoretically very limited because no general properties or attributes of the components (e.g., plant species assemblages, individual species) or processes (e.g., growth, reproduction, mineralization) of the system are used in any comprehensive way to generate predictive rules of wider than local relevance. Alternative approaches are suggested that would allow ecological generalizations and comparisons across systems.

Key Words: alternative stable states, climax, fire, grazing, retrogression, secondary succession

The senior author acknowledges support received from Texas Agricultural Experiment Station, Consejo Nacional de Investigaciones Cientficas y Técnicas (Argentina), Centro de Recursos Naturales Renovables de la Zona Semiárida (Argentina), and Fundacion Antorchas (Argentina). The contribution of unpublished material by various authors is gratefully acknowledged. Herman S. Mayeux, Jim C. Noble, and Imanuel Noy-Meir made helpful suggestions on an earlier version of the manuscript.

Manuscript accepted 14 Aug. 1996.
Resúmen

Descripciones de la dinámica de la vegetación natural del tipo "estados y transiciones" (ET) proveen información sobre percepciones actuales acerca de causas explícitas de cambio en vegetación dominante. Las caracteristicas estructurales de aplicaciones del modelo ET permiten una evaluación de su complejidad y comparaciones con la organización del modelo tradicional de sucesión secundaria, basado en secuencias de deterioro-sucesión. Un análisis de 29 aplicaciones del modelo ET reveló tendencias consistentes.

El incremento en el número de transiciones asociado a un aumento en el número de estados fue menor del esperado. Ello se deberia, probablemente, a limitaciones en la interpretación de relaciones complejas y a la necesidad de producir aplicaciones relativamente sencillas. Las aplicaciones de mayor tamaño tendieron a incluir estados estables centrales inmersos en estructuras menos conectadas (i.e. con menos transiciones) que lo esperable por azar para un cierto número de estados. Ello implicaria que algunos estados estables tienden a asumir roles intermediarios claves en aplicaciones que incluyen un elevado número de estados. Es discutible que ésta sea una propiedad de sistemas extensos o simple sesgo inducido en el uso del modelo.

El análisis de causas de camblo en la vegetación confirmó actuales percepciones acerca de la importancia de los disturbios antropogénicos. El pastoreo, el uso del fuego, y el control de especies leñosas aparecen como los más importantes agentes de cambio antropogénico. A pesar de ser dinámicamente controladas por eventos, algunas aplicaciones del modelo ET conservan elementos autogénicos. Los procesos autogénicos, sin embargo, aparecen desplazados de su rol central como causas universales de cambio en la vegetación. El valor teórico de esta propuesta es muy restringido porque no hace uso de propiedades o atributos de los componentes (e.g. especies, grupos de especies) o procesos (e.g. crecimiento, reproducción, mineralización) del sistema en alguna manera abarcadora que permita formular reglas predictivas de aplicación amplia. Se sugieren propuestas alternativas que permitirian generalizaciones ecológicas y comparaciones entre diferentes sistemas.

The state and transition (ST) model, named by Westoby et al. (1989a), has recently become a popular tool for communicating ideas and hypotheses about vegetation change in rangelands. For systems in which it may be meaningful to define ecological objects at a certain scale of perception, the ST model facilitates the capture of relevant system-driving events/processes. It also 
forces the suggestion or indication of explicit causes to justify transitions among states. Although the ST model lacks a spatial component, some of its most recent applications include statements about time frame, confidence, and expected probability of transitions (e.g., Ash et al. 1994).

Despite suggestions to the contrary (e.g., Borman and Pyke 1994), the ST model does not represent new ecological theory (Westoby et al. 1989b, Walker 1993). It has been used to describe vegetation dynamics that do not fit within the traditional succession-retrogression (SR) frame of vegetation change in rangelands described by Sampson $(1917,1919)$ and Dyksterhuis $(1949$, 1958a, 1958b) and this has probably generated some confusion. Applications of the ST model are frequently associated with "community" as opposed to "continuum" theories because of their structure, particularly the splitting of change processes into discrete states when systems are evaluated at pre-selected scales of time and space. This does not necessarily imply support for community-unit ecological theories; rather, it reflects an effort to simplify the translation of the supposedly complex operation of ecological objects into understandable diagrams amenable for management decisions. In particular, the dynamics of models presumably containing altemative stable states (for a theoretical view, see Law and Morton 1993) are usually depicted using this tool. This may be justified when the presence of alternative stable states, the occurrence of irreversible changes relative to the selected time scale, or the action of non-linear processes, are hypothesized.

A structural analysis of ST applications may provide an opportunity to evaluate differences and similarities between these "alternative stable state" schemes and traditional linear (Clements 1916, 1936) or star-like (Dyksterhuis 1949) representations of "climax-seral stage" models. The explicit implication of particular factors used to explain transitions between states offers a unique opportunity for cataloging and evaluating the relative frequency of causes of vegetation change and relationships among such causes. Sources of change of widespread apparent importance can be identified that may be relevant to consider when confronting the task of understanding range dynamics in similar vegetation types.

The objectives of this work were: (1) to identify causes of vegetation change of perceived widespread importance in rangelands, and (2) to assess the potential complexity of the state and transition model through an analysis of 29 applications of this approach. Some structural comparisons with the traditional succession-regression model were possible using regression techniques and graphical representations of a stage version of the SR model as the null hypothesis for the ST model.

\section{Materials and Methods}

Twenty nine published and unpublished applications of the state and transition model were analyzed (Table 1). Details on unpublished applications are available from the authors upon request. These studies represented the most complete set available and were not subjected to any selective process other than checking for "state and transition" structure and explicit indication of causes of transitions. Some of the studies (Whalley et al. 1978, Wilson et al. 1988, Silcock et al. 1988) predate the publication of the paper that is usually referred to as the original source for the scheme (Westoby et al. 1989a). Most of the models origi- nated in Australia, with some examples from Argentina, South Africa, Spain, and the US. These applications cover a fairly broad range of rainfall regimes and vegetation types, but most of them were developed for semi-arid grasslands/shrublands.

Clarification of some terms is required to interpret the analyses performed. A state and transition model contains 2 types of objects: states and transitions. States are physiognomically characterized ecological entities and are usually described by botanical composition of dominant vegetation. Transitions are not always clearly defined and may be classified as simple or complex. Simple transitions involve the action of only 1 possible cause (although it may have more than 1 component; chemical treatment of woody plants and grazing, for example) that may involve 1 or more single factors (e.g., chemical treatment of woody plants, grazing, rainfall, fertilization). Complex transitions may be provoked by more than one cause (grazing or rainfall and summer firc) each of which may involve 1 or more factors. Factors may be additionally characterized by some attribute (e.g., intensity, season) that completes their description. Complex transitions were distinguished from complex causes (those including more than 1 factor) by means of identifying 3 of the basic connectives of sentential logic in the model descriptions: negation ( $\neg$, i.e., no ), conjunction ( $\wedge$, i.e., and ) and disjunction ( $\vee$, i.e., or ). Stylistic variants of these connectives (e.g., both, although, as well as, unless) were interpreted and translated into 1 of the 3 logic equivalents (Allen and Hand 1992). Some examples follow.

Example 1: transition provoked by summer fire.

1 cause: fire

1 factor: fire (qualified by season)

Transition 1: (simple) provoked by factor $A$

1 cause: $A$ (simple)

1 factor: $A$

Example 2: transition provoked by no chemical control and no rain and heavy grazing.

Transition 2: (simple) provoked by $\neg A_{\wedge}\left(\neg B_{\wedge} C\right) 1$ cause: $\neg A \wedge(\neg B \wedge C)$ (complex);

3 factors: $A, B$, and $C$

Example 3: transition provoked by fire and no grazing or above average rainfall and seeding and no competition.

Transition 3: (complex) provoked by $\left(A_{\wedge} \neg B\right) \vee\left(C_{\wedge} D_{\wedge} \neg E\right)$

2 causes: $A \wedge \neg B$ (complex) or $C \wedge D \wedge \neg E$ (complex);

5 factors: A, B, C, D, E

The classification of factors and attributes causing vegetation change required many iterations. The classification developed is obviously not unique.

\section{Causes of Vegetation Change}

An analysis of causes of transitions was performed on the set of factors involved as qualified by attributes (a total of 50) and then grouped into 6 main factors determined from this preliminary general classification. Main factors identified were labeled as grazing, fire, rainfall, woody plant control, other man-related management practices, and endogenous factors. Causes identified as the "absence" or "lack" of single factors (e.g., fire, grazing) or combinations thereof (e.g., rainfall and grazing and no fire) were classified as endogenous based on the rationale that "absence of ..." or "lack of ..." implied that the system was left to its own spontaneous dynamics involving recruitment of new (possibly woody) plants, aging of perennial species, exhaustion of seed banks, and similar autogenic processes. It is recognized that, in some cases (e.g., purposive fire suppression), this assumption 
Table 1. Overview of main characteristics of models included in the data base of state and transition applications.

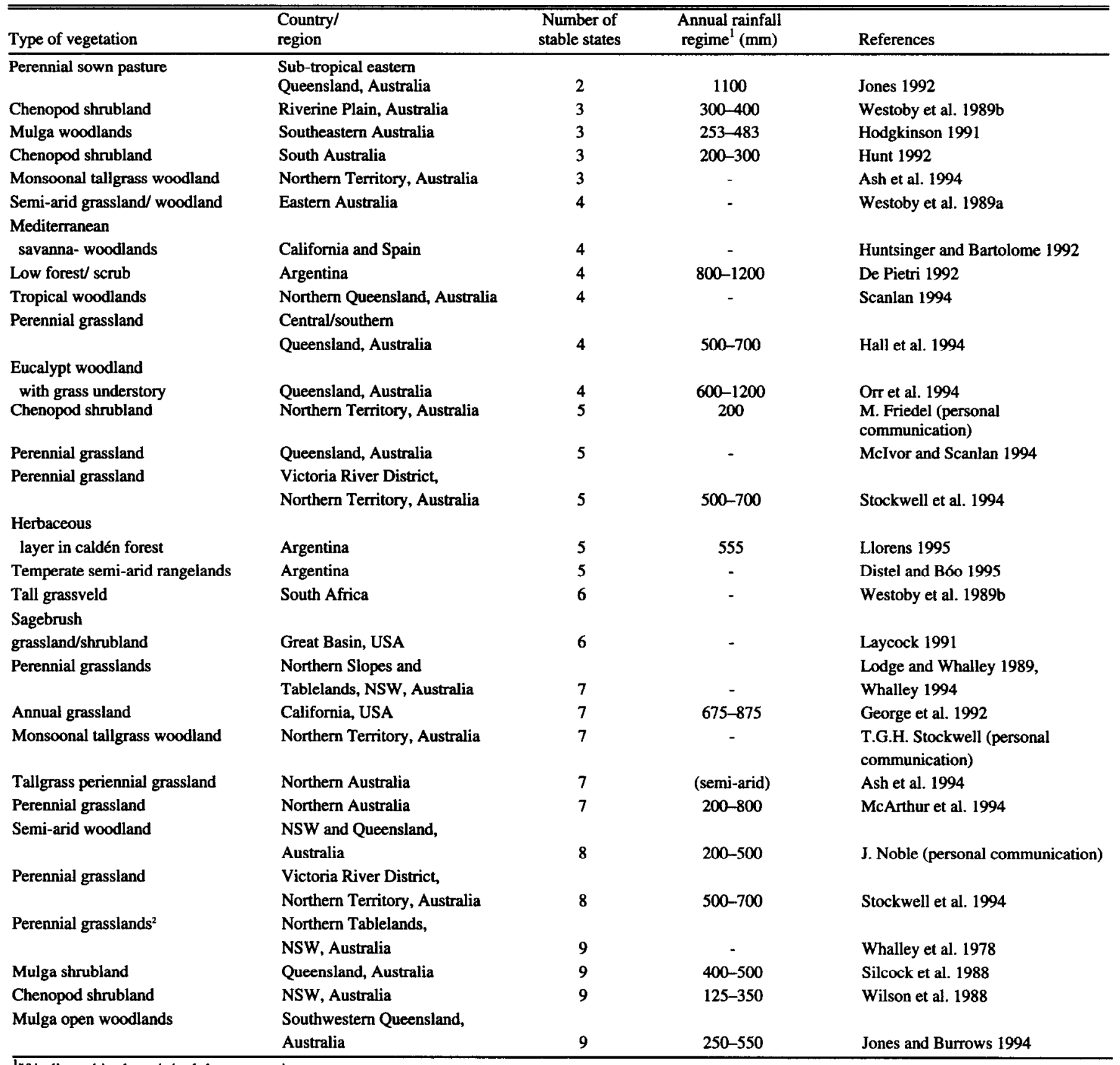

${ }^{1}$ If indicated in the original documentation.

${ }^{2}$ Model is an integrated view of 3 different perennial grasslands that were arbitrarily considered as a shole to avoid artificial replication of causes of vegetation change.

might introduce some bias. However, in an overwhelming majority of cases, the correct interpretation was that lack of fire, for example, implied the absence of conditions to apply prescribed burning when indicated. References to "climatic conditions" or "weather" (a total of 4 instances) were grouped under the "rainfall-general" label.

Causes involving 1,2 , and 3 or more single factors were classified independently and then pooled to obtain overall estimates of occurrences. A classification was also performed on complex causes involving exactly 2 or exactly 3 factors. This latter proce- dure allowed us to ascertain relationships between factors that are frequently cited in association. Results are expressed as occurrences (i.e., the number of times a particular factor or combination of factors was cited as involved in transitions) and/or frequencies (i.e., occurrences in relation to the total number of occurrences and expressed as percentages).

\section{Structural Analysis}

An analysis of some structural attributes of state and transition applications was implemented to study relationships involving 
the number of transitions, the degree of connection among states, and the distribution of transitions among states. Regression techniques and graphical representations of null hypotheses were used for these purposes. The rationale for this type of analysis was to evaluate the structural complexity of ST applications relative to a linear or star-like traditional stage-based "succession-retrogression" structure. This rationale requires clarification to avoid possible misinterpretations. Dyksterhuis' approach to range condition assessment (Dyksterhuis 1949, 1958a, 1958b) is based upon the succession-retrogression (SR) concept, but implemented in the context of a continuum in the vegetation space, i.e., no stages or states are distinguished (Dyksterhuis 1949, 1985). The widespread idea that Dyksterhuis' condition-relative-to-climax scheme is, somehow, "Clementsian" orthodoxy, is incorrect. However, and only for the purpose of comparing structural characteristics, SR was represented as linear or star-like sequences of states, more in line with a "traditional" view (e.g., Clements 1916, 1936; Sampson 1917, 1919).

For the representation of expected values and null hypotheses, the following results were used. The minimum number of transitions $(t)$ required to maintain the integrity of an application with $s$ states is $\mathbf{s - 1}$ (otherwise at least 1 state will be disconnected from the rest) and corresponds to a linear model (or some topologically equivalent structure) with only one transition linking consecutive states. The maximum number of transitions for an s-sized application of any possible structure is s ( s-1). Thus, an application with 3 states can have a maximum of up to 6 transitions that will connect each state to the rest through two-way links. The equivalent maximum possible number of transitions for an s-sized application with linear or topologically equivalent structure is 2 ( $s-1$ ). This is because links are only allowed between contiguous states. The degree of connectance (c) among states was calculated as the number of indicated transitions $(t)$ relative to the maximum number of possible transitions for a given size, i.e., $c=t /(s(s-1))$, which has a maximum of 1 (when all states are connected through two-way transitions) and a minimum of 1 / s (i.e., when the number of transitions is just enough to keep all states integrated). An estimate of connectance provides a way to evaluate the potential intricacy of the behavior of the system for a given nominal size. The null hypothesis for the expected value of connectance as a function of number of states required the calculation of a probability distribution for every possible number of stable states. For $s=2$, the maximum nurnber of possible transitions is 2 . These 2 transitions can be different or the same with the same probability $(0.5)$ only by chance. In the first case, $c=1 /(2(2-1))$ $=0.5$ while in the second one $c=1.0$, so the weighted (connectance values weighted by the probability of occurrence) mean outcome $(0.5 \times 0.5+1.0 \times 0.5)$ would be 0.75 . The process can be visualized as a random assignment of the maximum number of possible transitions for a given application size (of any possible structure, not necessarily linear) to the possible slots that transitions can occupy among states. A Monte Carlo approach, involving 10 replicates of 20,000 simulations for each nominal size (number of stable states) was used to estimate expected values of connectance.

The distribution of transitions, a measure of the concentration or dispersion of transitions among states, was estimated using an ad hoc equitability index (e) derived from Shannon's information index (Shannon and Weaver 1949):

$$
e=(\mathbf{H}-\mathbf{L}) / \mathbf{L}
$$

where $H$ is Shannon's index calculated as: $\quad H=-\sum_{i=1}^{s}\left(p_{i} \ln p_{i}\right)$; $s$ where $p_{i}=t_{i} / \Sigma t, t_{i}$ represents transitions as defined above, $i$ is $i^{\text {th }}$ state and $\mathrm{L}$ is $\mathrm{H}$ calculated for a model with completely reversible linear structure, i.e., one in which there would be 2 states (those located at both ends of the linear structure) connected to the rest by 2 transitions and (s-2) other states each connected by 4 transitions. This equitability index can be used as an indicator to detect structural shifts in the distribution of transitions which are indicative of certain states playing key "intermediary" roles in the dynamics of the system. Maximum equitability will vary with the number of stable states but can be easily calculated from configurations in which each state is connected to every other state by the same number of links, either 1 or 2 . Comparative minimum values of equitability were calculated using the following approach. For each nominal size, all possible configurations of linear and star-like reversible systems were determined and their frequencies and equitabilities calculated taking into account topologically equivalent configurations. A weighted (by frequency) average was then obtained for every possible number of stable states from 3 to 9 (equitability is fixed and equal to zero for a 2-state configuration).

\section{Results}

\section{Causes of Vegetation Change}

The 29 applications contained a total of 162 stable states (Table 1; mean: 5.6 states / application, range: 2-9 ). They provided a total of 310 transitions among states, 369 instances of causes of transitions, and 604 instances of factors involved in causes. In $1.2 \%$ of these latter instances (7/604) the ultimate factor involved was unknown to the author(s) or the corresponding transition was deemed improbable and the factor involved not identified. Table 2 shows occurrences and relative frequencies of main factors and individual factors within main factors, classified by causes involving one (192), two (264), or three or more (141) single factors. Only individual factors with at least $1.5 \%$ of overall frequency are shown in Table 2.

Grazing was the main factor most frequently cited (over $30 \%$ overall relative frequency) although its relative contribution decreased from over $40 \%$ to less than $20 \%$ as the number of factors involved in causes increased from 1 to 3 or more (Table 2). Endogenous factors were the second most frequently cited; they approached and finally exceeded the frequency of grazing factors as the number of factors considered increased. Rainfall was the third most frequently cited main factor and showed a trend to increase in relative frequency of citation as the number of factors involved in causes increased. The involvement of fire, woody plant control, and other man-related practices was lower and seemed to be less dependent on the number of factors included in causes although woody plant control increased up to $17 \%$ relative frequency when 3 or more factors were considered.

Grazing. A "within main factor" calculation of frequencies for grazing (Table 2 ) indicated a consistently high relative frequency of citation for intensity of grazing (either alone or interacting with season or system of grazing) that was not associated with the number of factors considered. Trampling, system of grazing, and an interaction factor between system of grazing and animal 
Table 2.Individual and main factors most frequently cited. Values are frequencies (occurrences) classified according to the number of factors involved in causes of transitions.

\begin{tabular}{|c|c|c|c|c|c|c|c|c|}
\hline \multirow{2}{*}{$\begin{array}{l}\text { Main Factor } \\
\text { Individual factor } \\
\end{array}$} & \multicolumn{8}{|c|}{ Number of factors involved in causes } \\
\hline & \multicolumn{2}{|c|}{ One } & \multicolumn{2}{|c|}{ Two } & \multicolumn{2}{|c|}{ Three or more } & \multicolumn{2}{|c|}{ All } \\
\hline $\begin{array}{l}\text { Grazing } \\
\text { by intensity } \\
\text { by system } x \text { intensity } \\
\text { by season } x \text { intensity } \\
\text { general } \\
\text { by season }\end{array}$ & $\begin{array}{r}43.2 \\
51.8 \\
18.1 \\
14.5 \\
7.2 \\
1.2\end{array}$ & $\begin{array}{r}(83) \\
(43) \\
(15) \\
(12) \\
(6) \\
(1)\end{array}$ & $\begin{array}{r}33.0 \\
66.7 \\
12.6 \\
3.4 \\
8.0 \\
6.9\end{array}$ & $\begin{array}{r}(87) \\
(58) \\
(11) \\
(3) \\
(7) \\
(6)\end{array}$ & $\begin{array}{r}19.9 \\
75.0 \\
0.0 \\
0.0 \\
7.1 \\
10.7\end{array}$ & $\begin{array}{l}(28) \\
(21) \\
(0) \\
(0) \\
(2) \\
(3)\end{array}$ & $\begin{array}{r}33.2 \\
61.6 \\
13.1 \\
7.6 \\
7.6 \\
5.1\end{array}$ & $\begin{array}{r}(198) \\
(122) \\
(26) \\
(15) \\
(15) \\
(10)\end{array}$ \\
\hline $\begin{array}{l}\text { Rainfall } \\
\text { above average } \\
\text { below average } \\
\text { general }\end{array}$ & $\begin{array}{r}11.5 \\
27.3 \\
50.0 \\
9.1\end{array}$ & $\begin{array}{r}(22) \\
(6) \\
(11) \\
(2)\end{array}$ & $\begin{array}{l}14.0 \\
24.3 \\
43.2 \\
13.5\end{array}$ & $\begin{array}{r}(37) \\
(9) \\
(16) \\
(5)\end{array}$ & $\begin{array}{r}21.3 \\
50.0 \\
6.7 \\
20.0\end{array}$ & $\begin{array}{r}(30) \\
(15) \\
(2) \\
(6)\end{array}$ & $\begin{array}{l}14.9 \\
33.7 \\
32.6 \\
14.6\end{array}$ & $\begin{array}{l}(89) \\
(30) \\
(29) \\
(13)\end{array}$ \\
\hline $\begin{array}{l}\text { Woody plant control } \\
\text { chemical } \\
\text { mechanical }\end{array}$ & $\begin{array}{r}6.3 \\
50.0 \\
25.0\end{array}$ & $\begin{array}{r}(12) \\
(6) \\
(3)\end{array}$ & $\begin{array}{r}5.7 \\
40.0 \\
53.3\end{array}$ & $\begin{array}{r}(15) \\
(6) \\
(8)\end{array}$ & $\begin{array}{l}17.0 \\
45.8 \\
50.0\end{array}$ & $\begin{array}{l}(24) \\
(11) \\
(12)\end{array}$ & $\begin{array}{r}8.5 \\
45.1 \\
45.1\end{array}$ & $\begin{array}{l}\text { (51) } \\
\text { (23) } \\
\text { (23) }\end{array}$ \\
\hline $\begin{array}{l}\text { Other man-related factors } \\
\text { seeding } \\
\text { fertilization }\end{array}$ & $\begin{array}{r}7.3 \\
21.4 \\
21.4 \\
\end{array}$ & $\begin{array}{r}(14) \\
(3) \\
(3) \\
\end{array}$ & $\begin{array}{r}9.1 \\
54.2 \\
29.2 \\
\end{array}$ & $\begin{array}{r}(24) \\
(13) \\
(7) \\
\end{array}$ & $\begin{array}{r}5.7 \\
62.5 \\
0.0 \\
\end{array}$ & $\begin{array}{l}(8) \\
(5) \\
(0) \\
\end{array}$ & $\begin{array}{r}7.7 \\
45.7 \\
21.7 \\
\end{array}$ & $\begin{array}{l}(46) \\
(21) \\
(10) \\
\end{array}$ \\
\hline
\end{tabular}

Endogenous. The "endogenous" main factor had the largest number and variety of individual factors included. Availability of seed/propagules was the individual factor most frequently referred to within this group although it was never mentioned as the only factor responsible for any transition (Table 2). Other, less frequently mentioned individual factors were insect outbreaks, absence of various complex causes, establishment of exotics/invaders, competition and absence of competition, plant diseases, increased above ground primary production, plant dieback, soil surface conditions, and absence of cultivation. The absence of a factor (e.g., no fire, no grazing) was the most frequently invoked cause of change within this group, accounting for over 50\% (72/139) of all instances. When this uninformative composite factor was removed from calculations, the frequency of citation of seed bank status increased to $54.2 \%$ ( $39 / 72)$ with similar incidences when $2(22 / 41)$ or 3 or more $(17 / 22)$ individual factors were considered.

Rainfall and Fire. These main factors were cited a similar number of times (Table 2) although the internal distribution within main factors was remarkably different. Most frequent references involving rainfall mentioned lack of rain (or drought) and above average precipitation (or some stylistic variants) with rainfall as a general event mentioned less frequently (Table 2). Also, opposite trends with the number of individual factors involved were observed for above and below average precipitation. Season, timing of rain, timing of rain interacting with amount of rainfall, and season interacting with amount of rainfall accounted for the rest of the occurrences within this main factor.

Fire was rarely qualified as dependent on the usual attributes of season, frequency, and intensity (Table 2) and interactions between those attributes were only mentioned in 3 instances of fire involvement. Wildfires or wildfire control, intensity of fire, and an interaction between frequency and intensity of fire complete the list of individual fire-related factors.

Woody Plant Control and Other Man-related Factors. Patterns of relative frequency within the "woody plant control" and "other" groups are probably much less reliable because of the reduced number of instances involved. Nevertheless, similar frequencies of chemical and mechanical control of woody plants were observed (Table 2), with biological control and plant control as a general factor, less frequently considered. Man-related factors other than those indicated in Table 2 were overharvest of propagules, soil reclamation, cultivation, and weeding.

Pairs of Factors. Main factors most frequently mentioned together included grazing and endogenous factors, grazing and fire, and grazing and rainfall (Table 3). Marginal frequencies (last column in Table 3) differ slightly from the distribution of twofactor causes in Table 2 because contributions from pairs constituted by the same factor count double in Table 3. Results from the occurrence of three-factor causes (117 instances) followed similar trends with grazing, rainfall, and endogenous as the most important groups of factors $(59.0,56.4$, and $51.3 \%$, respectively), followed by woody plant control ( $46.1 \%)$, fire (38.5\%), and other man-related practices $(12.8 \%)$.

Frequency of main factors varied among applications, and for those with 3 or more states, there was no apparent pattern of change associated with the number of states (Fig. 1). Frequency of endogenous factors tended to follow an inverse trend relative to grazing factors. Rainfall and grazing were the only factors mentioned in the 2-state application included in the analysis (Fig. 1). 
Table 3. Occurrence (frequency) of different pairs of factors as causes of transitions. Individual factors are grouped under endogenous, fire, graxing, rainfall, woody plant control (WPC), and other man-related main factor labels.

\begin{tabular}{|c|c|c|c|c|c|c|c|}
\hline & Grazing & Endogenous & Fine & Rainfall & Other (man) & WPC & $\begin{array}{c}\text { Overall } \\
\text { Frequency }\end{array}$ \\
\hline Grazing & $1(0.8)$ & $34(25.8)$ & $22(16.7)$ & $20(15.1)$ & $2(1.5)$ & $7(5.3)$ & 65.1 \\
\hline Endogenous & & $11(8.3)$ & $3(2.3)$ & $7(5.3)$ & $1(0.8)$ & $0(0.0)$ & 42.4 \\
\hline Rainfall & & & & $2(1.5)$ & $2(1.5)$ & $0(0.0)$ & 26.5 \\
\hline Other (man) & & & & & $8(6.1)$ & $3(2.3)$ & 12.1 \\
\hline WPC & & & & & & $0(0.0)$ & 11.4 \\
\hline
\end{tabular}

'Last column shows the overall frequency of occurrence of each main factor relative to the total number of pairs (132).

\section{Structural Analysis}

Results from structural analyses are summarized in Figs. 2 to 4. As expected, the number of transitions increased with the number of states although 2 of the applications only exhibited enough transitions to exactly keep the integrity corresponding to their nominal size (Fig. 2). A linear regression of number of transitions against number of states in $\log$-log scale was found to adequately describe this relationship $(P<0.001, r=0.73)$ and attenuated an increase in variance associated with the number of states. Nonlinear alternatives did not improve this fit significantly. The slope of this relationship in the linear scale $(1.82 \pm 0.322 ; b \pm \mathrm{SE})$ was compared to the expected value for applications with linear or topologically equivalent structure (i.e., 2) and found not significantly different $(t=0.56 ; 27$ d.f.). The theoretical intercept (i.e., -2) was within the standard error of the calculated intercept $(0.04$ $\pm 1.921)$ and consequently not significantly different from it $(t=$ 1.06; 27 d.f.). Points corresponding to applications with minimum numbers of transitions for their nominal size (Fig. 2) showed up as potential outliers in many diagnostic plots, even in $\log$-log scale. Removing those data, however, did not change any result so they were retained.

Average connectance among states tended to decrease with an increase in the number of states (Fig. 3). Average connectance was close to theoretical expected values for applications with few states but declined, approaching minimum connectance, as the

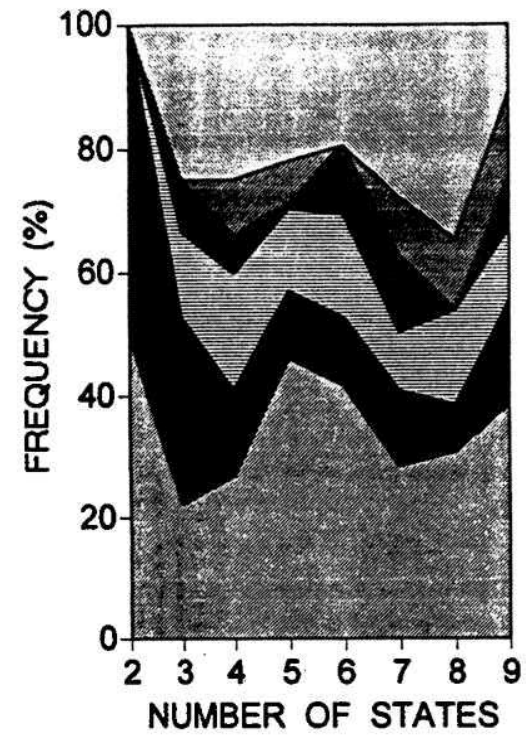

\begin{tabular}{|l|}
\hline$\square$ Endogenous \\
WP control \\
Other (man) \\
圊 Fire \\
Rainfall \\
Grazing \\
\hline
\end{tabular}

Fig. 1. Relative frequencies of main factors involved in transitions as a function of the number of stable states. number of states increased. The equitability index (Fig. 4) showed similar behavior. Applications with 4 or fewer stable states exhibited null or positive deviations (i.e., more uniform distribution of links than with a linear or topologically equivalent reversible structure) except for 1 case, while applications with 5 or more states showed increasingly negative deviations.

\section{Discussion}

Although the set of state and transition applications analyzed does not represent any particular ecological system or region, some general structural features can be characterized and applied for developing other applications. The relative frequency of factors cited as causes of vegetation change in this collection of ST applications does not necessarily apply in general to rangelands, but does reflect current main-stream range management ideas (Stafford Smith and Pickup 1993). The high relative frequencies with which certain factors and groups of factors were cited is a

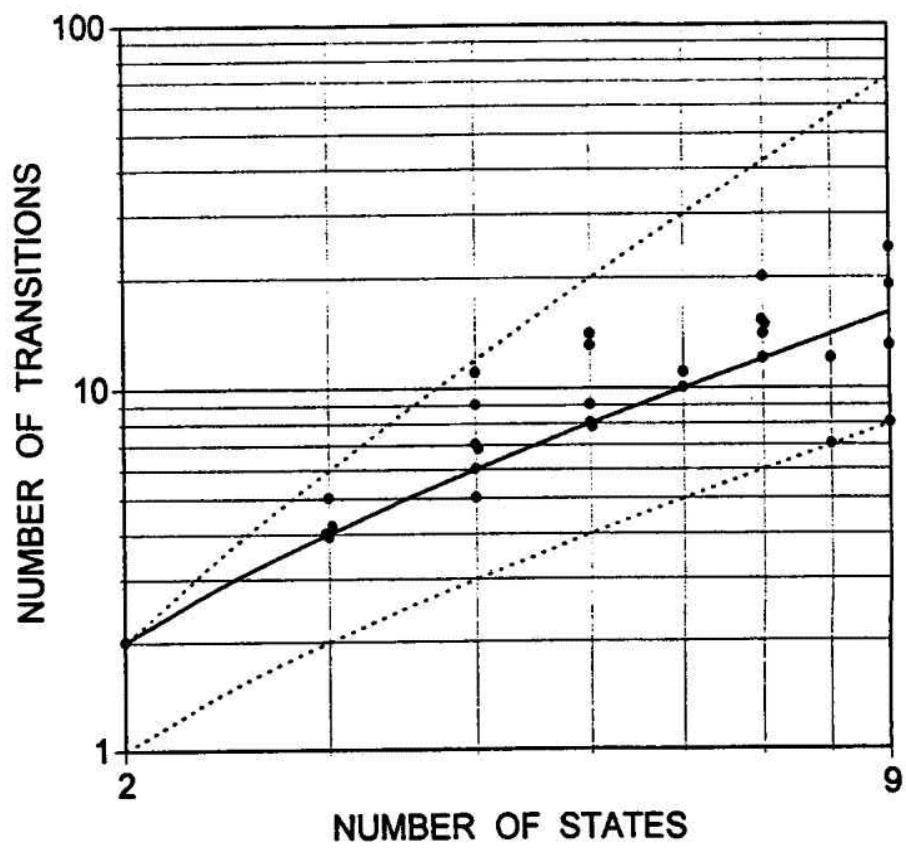

Fig. 2. Observations (black symbols) and expected relationship (solid line) describing the number of transitions as a function of the number of stable states under the assumption of linear (or topologically equivalent) structure. Dotted lines indicate allowable maxima and minima for the observations. Clumped observations (number of states 3, 4, 5, and 7) were jittered by adding random noise to improve visualization. 


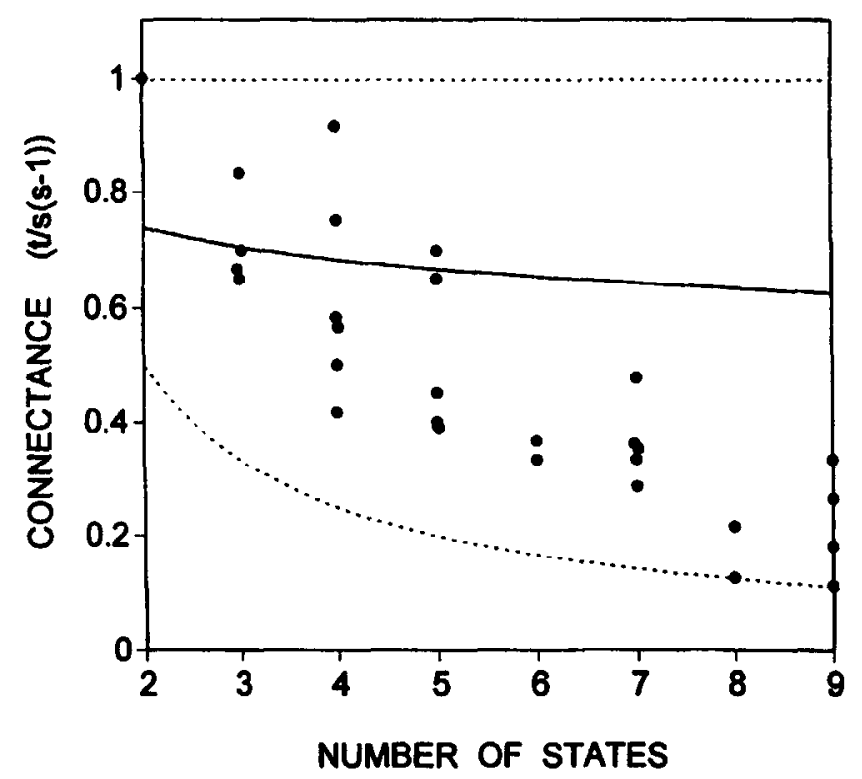

Fig. 3. Observed (black symbols) and expected (solid line) values for connectance. Maximum and minimum values allowable are indicated by the dotted lines. Clumped observations (number of states $3,4,5$, and 7 ) were jittered by adding random noise to improve visualization.

consequence of their perceived widespread importance across a variety of rangeland types (see Fig. 1). In this sense, sources of change frequently mentioned in these applications should be considered when evaluating the dynamics of similar types of rangelands.

\section{Causes of Vegetation Change}

Among the factors that can be controlled by management, intensity of grazing is obviously considered the most important single cause of vegetation change followed by the use of fire. Other management practices like chemical or mechanical woody plant control and seeding account for a much reduced relative frequency of citation. However, when considered as a whole, manrelated factors justify more than $60 \%$ (364/597) of the total number of instances of identified factors. Rainfall (15\%) and endogenous factors (23\%) account for the rest. Although this partition depends on a non-unique classification of individual factors, it is surprising that about $20 \%$ (38/192) of simple instances of transitions and $23 \%$ of the total were attributed to the action of autogenic factors. This is hardly expected for system components that are supposed to remain relatively stable when external forces are not operating (Laycock 1991). Some of the endogenous "factors" cited (e.g., availability of propagules) may well be considered conditions required for the operation of other factors, rather than genuine and ultimate causes of change. However, almost half (68/139) of the instances included in the "endogenous" group of factors corresponded to cases of "absence of ...", particularly of grazing or fire. This is a clear indication that certain spontaneous behavior still remains embedded in the structure of some ST applications, even if not explicitly modeled.

Two trends were observed relative to the number of factors considered. The overwhelming frequency of citation of grazing when only single factors are considered was moderated by an increasing relevance of factors such as seed bank dynamics (Table 2) up to a point in which grazing was no longer the most frequently cited main factor. Above and below average rainfall regimes exhibited opposite trends associated with the number of factors considered (Table 2). This probably reflects the fact that droughts can severely modify the botanical composition of a site by themselves while a good rain needs to be accompanied by other factors or conditions, like availability of propagules or a reduction of stocking rate, to produce similar effects.

The analysis of pairs of factors (Table 3) was in general agreement with the trends discussed above. Additive, interactive or sequential effects involving grazing seem to be the most common instances of complex factors.

\section{Structural Analysis}

The structural analyses revealed an economy of transitions between states remarkably similar to what would be expected for linear or star-like succession-retrogression models of comparable dimensions (Fig. 2). Accordingly, the likelihood of transition from a given state towards any other possible state was proportionally lower for larger state and transition applications (Fig. 3). A similar phenomenon is usually observed in ecological webs (Yodzis 1980, Warren 1994), although in this latter case it may well be due to defective sampling. In our case, the observed decrease in connectance may indicate a real trend associated with an increase in the complexity of the applications. Alternatively, and more probably, it reflects human limitations to visualize complex systems. The decrease in connectance was associated with a shift in the distribution of transitions (Fig. 4) from applications with states more evenly connected than expected for a reversible linear structure towards applications with a more biased distribution of transitions among states. This indicates that some stable states tend to assume central or key roles as the number of states considered increases. With climax removed from its central role as the reference state in succession-deterioration sequences, more equitability among states would be expected. A

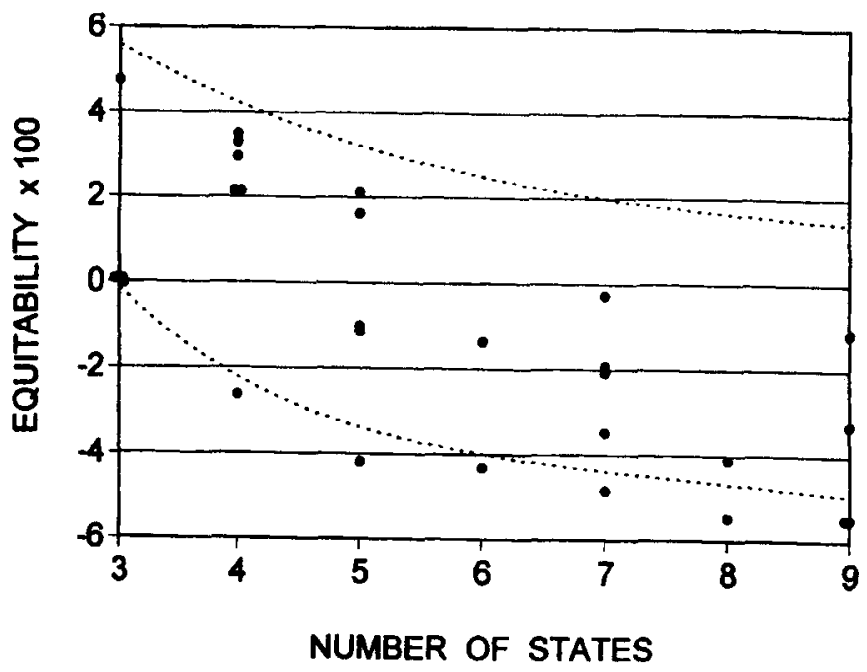

Fig. 4. Observed values for the equitability index as a function of the number of stable states. Maximum and minimum values allowable for linear or topologically equivalent structures are indicated by dotted lines. Clumped observations (number of states 3, 4, and 5) were jittered by adding random noise to improve visualization. 
possible explanation is that those central intermediary states are the best known or the ones most frequently observed under current management conditions. Familiarity with a certain common state of the vegetation may bias the general picture of the system. Again, it is difficult to ascertain to what extent a decreased equitability is a real property of larger systems or simply an effect of the way human minds look at the world. Some of the structural properties observed may be more related to the psychology of perception than to any real characteristic of increasingly complex systems.

Two striking outcomes from these analyses are the elementary nature of causes of change and the structural simplicity of the applications. More than half of the instances of transitions for which some explanation was provided involved only 1 factor (206/359), possibly modified by the attachment of some attribute. In $90 \%$ of the instances (324/359), transitions were associated with at most 2 factors. In only $2 \%$ of the cases were transitions justified by the action of complex causes involving 4 factors. In addition, wording of complex causes involving 2 or more factors generally corresponded to a mental image of additivity or sequential effects rather than of interactions among factors. This is in sharp contrast with the generally acknowledged complexity of vegetation dynamics (Roberts 1987, Wiegleb 1989) and reveals the equivalent of a statistical "main effects" linear model operating at each node (stable state) in state and transition applications. The reasonableness of this approach may well be justified in the necessity of providing unsophisticated management-level predictions and/or in the lack of a consistent ecological theory about the spontaneous behavior of complex ecological objects.

The dynamic represented in Fig. 5 is a good example of how spontaneous and "external" causes of change are weighted in ST applications. Fig. 5 is a modification of Fig. 5 from Westoby et al. (1989b) in which all man-related causes of change have been removed. According to what is left from the original ST application, in a hands-off scenario and given enough time, the system would tend to reach a unique stable state that would persist unless the system were put under some disturbance stress. Many ST applications can be reduced to similar schemes by means of removing identifiable "non-spontaneous" causes of change. What is usually left, in turn, is very similar to traditional succession schemes in which a certain sequence of seral stages, terminating in a unique stable state, was hypothesized to represent the sponta-

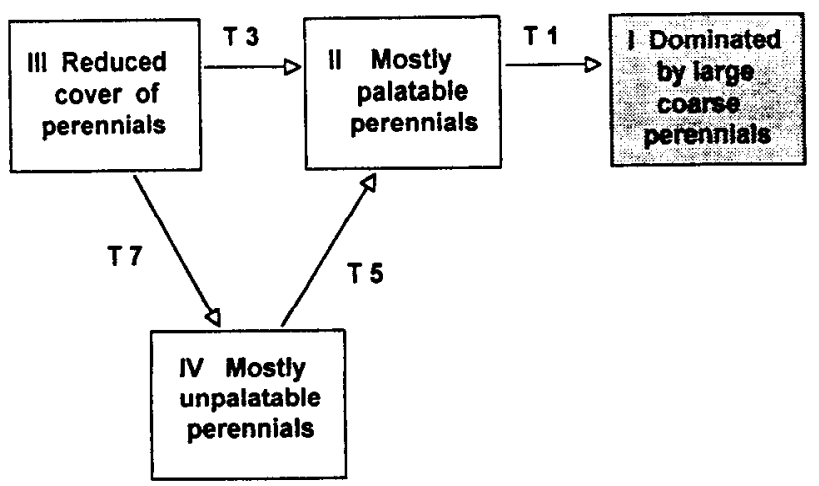

Fig. 5. ST application from Westoby et al. (1989b, Fig. 5), modified by removing transitions provoked by man-related causes of vegetation change. neous behavior of the system when freed from disturbances. Thus, compared to traditional seral stages-climax ideas, the ST approach shifts the relative importance of causes of change by means of overweighing identifiable man-caused factors and downplaying autogenic factors like modifications of soil properties and competition. In doing this, however, the power of an all-encompassing theory of ecological system behavior is lost and replaced by ad hoc local shifts that fit previously observed vegetation changes under the influence of local prevailing disturbance forces. This may be realistic, but it is also theoretically very limited because no general properties or attributes of the components (e.g., plant species assemblages, individual species) or processes (e.g., growth, reproduction, mineralization) of the system are used in any general way to generate prediction rules of wider than local relevance. The cohesive nature contributed by processes involved in autogenic succession is removed from its central role of providing a coherent general reason for vegetation change but no alternative comprehensive properties are invoked to fill the gap.

The closest thing to a theoretical support for favoring state and transition representations of ecological systems is provided by the hypothesized existence of alternative stable states in those systems (Lewontin 1969, Sutherland 1974). A thorough discussion of this subject is out of the scope of the present paper but a brief comment on it is worthwhile. The existence of alternative stable states in very simple mathematical systems (see, for example, Noy-Meir 1975) has been widely invoked as evidence favoring the possible occurrence of alternative stable states in complex ecological systems (see, for example, Scheffer et al. 1993). This is a misleading assumption. No general principle can be invoked to justify any similarity between the behavior of a closed isolated mathematical system and the functioning of an open real complex adaptive system with diffuse boundaries. There is no evident reason to assume that more complex entities than those usually represented by Lotka-Volterra equations or similar predator-prey dynamics would behave in a similar way. In fact, empirical evidence frequently shows that the opposite may be true due to compensating effects induced by interactions with other systems within a common local landscape. Thus, general equilibrium conditions may emerge asymptotically at certain spatial scales (DeAngelis and Waterhouse 1987).

The correct interpretation of Noy-Meir's graphical exercise (Noy-Meir 1975) is that simplicity does not preclude the possible existence of alternative stable states in grazing systems if the assumptions and strong simplifications embedded in the mathematical abstraction are tenable. However, what is a "state" and what is "stable" depends primarily on our perception of change; i.e., on the temporal and spatial scale at which abstractions of reality are being produced. In this sense, it may be fruitful to dissect a system's behavior into discrete states, if looking at its functioning at such a scale facilitates interpretation and management decisions. This procedure does not require theoretical justification.

Producing theoretical support in the form of unifying ecological principles with predictive capability, based upon the concept of discrete states, is a different, yet unsolved problem (Stafford Smith 1992). Some examples of possibly alternative stable states have been reported in various ecosystems (Barkai and McQuaid 1988, Dublin et al., 1990, Scheffer et al. 1993) but the question still remains whether the nature of those states is dependent upon the intrinsic dynamic of the ecological objects or, in contrast, whether they are produced by some "external" forces alien to the 
alien to the undisturbed or unexploited system (Connell and Souza 1983). Thus, Dublin et al. (1990) considered elephants (apparently a true component of the system) as agents able to maintain the grassland state in the Serengeti-Mara woodlands ecosystem but they claimed that such a state was only produced by fire, an "external" perturbation according to the authors.

\section{Summary and Conclusions}

The set of state and transition applications analyzed revealed the following general characteristics:

1) ST applications are structurally similar to traditional linear "climax-seral stages" succession-retrogression models. However, other important differences are the rejection of complete reversibility embedded in the traditional view of secondary succession and the explicit treatment of other causes of vegetation change, in addition to grazing.

2) The lack of an expected more-than-proportional increase in transitions in response to an increased number of states may be due to some yet unknown property of the type of systems studied, a consequence of the necessity to keep models simple, or the result of human intellectual limitations to elucidate complex relationships.

3) Bigger applications tended to be centered around stable states that would play key roles as a consequence of their pivotal position within structures less connected than expected by chance for a given number of states.

The analysis of causes of change confirmed current perceptions concerning the apparent overwhelming importance of man-related sources of vegetation change in rangelands. In particular, grazing, fire, and woody plant control are visualized as the most relevant man-related agents of change. Some spontaneous behavior, not explicitly modeled, remains hidden in the definition of transitions in many ST applications.

If we are going to produce meaningful and comparable observational evidence regarding vegetation change, the nature of the boundaries between spontaneous and induced (by "external" forces) behaviors of ecological objects needs to be defined for previously selected scales of time and space. Those boundaries are blurred in the ST model by a lack of underlying support in the form of a general explanatory theory (sensu Hempel and Oppenheim 1948) that would link and generalize what otherwise is a collection of ad hoc site-specific hypotheses. Alternative approaches, based upon comprehensive properties of the elements or processes involved in rangeland systems, are required for updating currently unsatisfactory paradigms. Response and assembly rules based upon ecologically meaningful species traits (Keddy 1990, 1992a, 1992b) are probably the most promising alternatives. Response rules to the major disturbance factors discussed in this paper may be derived from currently available expert knowledge and generalized for application in similar ecosystems by means of relating responses to adaptive species profiles (Rodríguez Iglesias 1996). The challenge is to integrate models of autogenic behavior with management-level models driven by disturbance events/regimes and inputs. The ST model may provide phenomenological background for local applications, but truly explanatory models will require the integration of autecological information on individual species and processes involved in the observed responses to disturbance agents.

\section{Literature Cited}

Allen, C. and M. Hand. 1992. Logic primer. MIT Press, Cambridge, Mass.

Ash, A.J., J.A. Bellamy, and T.G.H. Stockwell. 1994. State and transition models for rangelands. 4. Application of state and transition models to rangelands in northern Australia. Trop. Grassl. 28:223-228.

Barkai, A. and C. McQuaid. 1988. Predator-prey role reversal in a marine benthic ecosystem. Sci. 242:62-64.

Borman, M.M. and D.A. Pyke. 1994. Successional theory and the desired plant community approach. Rangelands 16:82-84.

Clements, F.E. 1916. Plant succession. Carnegie Inst. Wash. Publ. 242.

Clements, F.E. 1936. Nature and structure of the climax. J. Ecol. 24:252-284.

Connell, J.H. and W.P. Souza. 1983. On the evidence needed to judge ecological stability or persistence. Amer. Natur. 121:789-824.

DeAngelis, D.L. and J.C. Waterhouse. 1987. Equilibrium and nonequilibrium concepts in ecological models. Ecol. Monogr. 57:1-21.

De Pietri, D.E. 1992. The search for ecological indicators: is it possible to biomonitor forest system degradation caused by cattle ranching activities in Argentina? Vegetatio 101:109-121.

Distel, R.A. and R.M. Bóo. 1995. Vegetation states and transitions in temperate semiarid rangelands of Argentina. p. 17. In: N. West, (ed.) Proceedings of the V International Rangeland Congress. Salt Lake City, Ut.

Dublin, H.T., A.R.E. Sinclair, and J. McGlade. 1990. Elephants and fire as causes of multiple stable states in the Serengeti-Mara woodlands. J. Anim. Ecol. 59:1147-1164.

Dyksterhuis, E.J. 1949. Condition and management of rangeland based on quantitative ecology. J. Range Manage. 2:104-115.

Dyksterhuis, E.J. 1958a. Ecological principles in range evaluation. Bot. Rev. 14:253-272.

Dyksterhuis, EJ. 1958b. Range conservation as based on sites and condition classes. J. Soil Water Conserv. 13:151-155.

Dyksterhuis, E.J. 1985. Follow-up on range sites and condition classes as based on quantitative ecology. Rangelands 7:172-153.

George, M.R., J.R. Brown, and W.J. Clawson. 1992. Application of nonequilibrium ecology to management of Mediterranean grasslands. J. Range Manage. 45:436-440.

Hall, T.J., P.G. Filet, B. Banks, and R.G. Silcock. 1994. State and transition models for rangelands. 11. A state and transition model of the Aristida-Bothriochloa pasture community of central and southern Queensland. Trop. Grassl. 28:270-273.

Hempel, C.G. and P. Oppenheim. 1948. Studies in the logic of explanation. Philosophy of Sci. 15:567-579.

Hodgkinson, K.C. 1991. Identification of critical thresholds for opportunistic management of rangeland vegetation. p. 127-129. IV Congrès International des Terres de Parcours, Montpellier, France.

Hunt, L.P. 1992. Piospheres and the state-and-transition model of vegetation change in chenopod shrublands. p. 37-45. Proceedings of the 7th Australian Rangeland Society Conference, Cobar, Australia.

Huntsinger, L. and J.W. Bartolome. 1992. Ecological dynamics of Quercus dominated woodlands in California and southern Spain: a state-transition model. Vegetatio 100:299-305.

Jones, P. 1992. Resting from grazing to reverse changes in sown pasture composition: application of the 'state-and-transition' model. Trop. Grassl. 26:97-99.

Jones, P. and W.H. Burrows. 1994. State and transition models for rangelands. 13. A state and transition model for the mulga zone of south-west Queensland. Trop. Grassl. 28:279-283.

Keddy, P.A. 1990. The use of functional as opposed to phylogenetic systematics: a first step in predictive community ecology. pp. 387-406. In: Kawano, S. (ed.). Biological approaches and evolutionary trends in plants. Academic Press, Harcourt Brace Jovanovich, London, UK.

Keddy, P.A. 1992a. Assembly and response rules: two goals for predictive community ecology. J. of Veg. Sci. 3:157-164.

Keddy, P.A. 1992b. A pragmatic approach to functional ecology. Functional Ecol. 6:621-626.

Laycock, W.A. 1991. Stable states and thresholds of range condition on North American rangelands: a viewpoint. J. Range Manage. 44:427-433. 
Law, R. and R.D. Morton. 1993. Alternative permanent states of ecological communities. Ecol. 74:1347-1361.

Lewontin, R.C. 1969. The meaning of stability. Brookhaven Symp. Biol. 22:13-24.

Llorens, E.M. 1995. Viewpoint: the state and transition model applied to the herbaceous layer of Argentina's calden forest. J. Range Manage. 48:442-447.

Lodge, G.M. and Whalley, R.D.B. 1989. Native and natural pastures of the Northern Slopes and Tablelands of New South Wales: A review and annotated bibliography. Technical Bulletin No. 35. NSW Agriculture and Fisheries, Sidney, Australia.

McArthur, S.R., H.J. Chamberlain, and D.G. Phelps. 1994. State and transition models for rangelands. 12. A general state and transition model for the mitchell grass, bluegrass-browntop and Queensland bluegrass pasture zones of northern Australia. Trop. Grassl. 28: 274-278.

McIvor, J.C. and Scanlan, J.C. 1994. State and transition models for rangelands. 8. A state and transition model for the northern speargrass zone. Trop. Grassl. 28:256-259.

Noy-Meir, 1. 1975. Stability of grazing systems: an application of predator-prey graphs. J. Ecol. 63:459-481.

Orr, D.M., C.J. Paton, and S. McIntyre. 1994. State and transition models for rangelands. 10. A state and transition model for the southern black speargrass zone of Queensland. Trop. Grassl. 28:266-269.

Roberts, D.W. 1987. A dynamical systems perspective on vegetation theory. Vegetatio 69:27-33.

Rodriguez Iglesias, R.M. 1996. A formalism for characterizing vegetation responses using classification trees and Dempster-Shafer theory of evidence. Ph.D. Diss.. Texas A\&M Univ., College Station, Tex.

Sampson, A.W. 1917. Succession as a factor in range management. J. For. 15:539-596.

Sampson, A.W. 1919. Plant succession in relation to range management. U.S. Dept. Agr., Bull. 791.

Scanlan, J.C. 1994. State and transition models for rangelands. 5. The use of state and transition models for predicting vegetation change in rangelands. Trop. Grassl. 28:229-240.

Scheffer, M., S.H. Hosper, M-L. Meijer, B. Moss, and E. Jeppesen. 1993. Alternative equilibria in shallow lakes. TREE 8: 275-279.

Shannon, C.E. and W. Weaver. 1949. The mathematical theory of communication. The University of Illinois Press, Urbana, Ill

Silcock, R.G., R.F. Brown, and M. McKeon. 1988. Effects of plant morphology and physiology on native pasture management. pp.34-51. In: Native pastures in Queensland. Queensland Department of Primary Industries, Information Series QI1877023.

Stafiord Smith, D.M. 1992. Successors in succession. Bulletin of the Ecological Society of Australia 22: 27-29.

Stafford Smith, D.M. and G. Pickup. 1993. Out of Africa, looking in: understanding vegetation change. pp. 196-226. In: R.H. Behnke Jr., I. Scoones, and C. Kerven (eds.), Range ecology at disequilibrium. Overseas Development Institute, London, UK.

Stockwell, T.G.H., R.T. Andison, A.J. Ash, J.A. Bellamy, and R.M. Dyer. 1994. State and transition models for rangelands. 9. Development of state and transition models for pastoral management of the golden beard grass and limestone grass pasture lands of NW Australia. Trop. Grassl. 28:260-265.

Sutherland, J.P. 1974. Multiple stable points in natural communities. Amer. Natur. 108:859-873

Walker, B.H. 1993. Stability in rangelands: ecology and economics. p. 1885-1890. In: Proceedings of the XVII International Grassland Congress, Palmerston North, Hamilton, Lincoln, NZ and Rockhampton, Australia.

Warren, P.H. 1994. Making connections in food webs. TREE 9:136-141.

Westoby, M., B. Walker, and I. Noy-Meir. 1989a. Opportunistic management for rangelands not at equilibrium. J. Range Manage. 42:266-274.

Westoby, M., B. Walker, and I. Noy-Meir. 198\%b. Range management on the basis of a model which does not seek to establish equilibrium. J. Arid Environ. 17:235-239.

Whalley, R.D.B. 1994. State and transition models for rangelands. 1. Successional theory and vegetation change. Trop. Grassl. 28:195-205.
Whalley, R.D.B., G.G. Robinson, and J.A. Taylor. 1978. General effects of management and grazing by domestic livestock on the rangelands of the Northern Tablelands of New South Wales. Aust. Rangel. J. 1:174-190.

Wiegleb, G. 1989. Explanation and prediction in vegetation science. Vegetatio 83:17-34.

Wilson, A.D., K.C. Hodgkinson, and J.C. Noble. 1988. Vegetation attributes and their application to the management of Australian rangelands. pp. 253-294. In: P.T. Tueller (ed.), Vegetation science applications for rangeland analysis and management. Kluwer Academic Publishers, London, UK.

Yodzis, P. 1980. The connectance of real ecosystems. Nature 284:544-545. 